\section{A Constituição Cidadã e os 25 anos do Sistema Único de Saúde (SUS)}

\author{
The Citizen Constitution and the 25th anniversary \\ of the Brazilian Unified National Health System \\ (SUS)
}

\section{La Constitución ciudadana y el 25o aniversario del Sistema Único de Salud brasileño (SUS)}

\author{
1 Instituto de Saúde Coletiva \\ Universidade Federal da \\ Bahia, Salvador, Brasil. \\ Correspondência \\ J. S. Paim \\ Instituto de Saúde Coletiva \\ Universidade Federal da \\ Bahia. \\ Rua Basílio da Gama s/n, \\ Salvador, BA 40110-170, \\ Brasil. \\ jairnil@ufba.br
}

\begin{abstract}
This article, celebrating the 25th anniversary of Brazil's 1988 Constitution, aims to review the country's social policy development, discuss political projects, and analyze challenges for the sustainability of the Unified National Health System (SUS). Based on public policymaking studies, the article revisits the origins of liberal social policy, focused on social assistance, and analyzes the hegemony of U.S. policies targeting poverty and their repercussions for universal policies. After identifying the formulation of political projects in Brazil's democratic transition, it discusses their implications during the various Administrations since 1988, along with the difficulties faced by the National Health System. The article concludes that the political forces occupying government in the last two decades have failed to present a project for the country on the same level as those who drafted the Citizen Constitution.
\end{abstract}

Health Policy; Health Systems; Unified Health System; Public Policy
Jairnilson Silva Paim 1

\section{Resumo}

Este artigo, comemorando 25 anos da Constituição Federal de 1988, teve como objetivos resenhar o desenvolvimento das políticas sociais, discutir projetos políticos e analisar desafios para a sustentabilidade do Sistema Único de Saúde (SUS). Apoiando-se em estudos sobre políticas públicas que privilegiam a gênese, revisita as origens da política social liberal, centrada na assistência social, e analisa a hegemonia das políticas americanas voltadas para a pobreza e suas repercussões nas políticas universais. Após identificar a formulação de projetos políticos na transição democrática brasileira, discute seus desdobramentos nos governos seguintes, juntamente com as dificuldades enfrentadas pelo SUS. Conclui que as forças politicas que alcançaram o poder nas duas últimas décadas não apresentaram um projeto para a Nação à altura daqueles que geraram a Constituição Cidadã.

Política de Saúde; Sistemas de Saúde; Sistema Único de Saúde; Política Social 
“A crítica arrancou as flores imaginárias que enfeitavam as cadeias, não para que o homem use as cadeias sem qualquer fantasia ou consolação, mas para que se liberte das cadeias e apanhe a flor viva" (Karl Marx 1, p. 146-7).

\section{Introdução}

Cinco de outubro de 2013 é uma data em que a sociedade brasileira celebra 25 anos da Constituição Cidadã, renovando o compromisso e a esperança de transformar cada brasileiro em sujeito de direitos.

A Constituição Federal de 1988 incorporou uma concepção de seguridade social como expressão dos direitos sociais inerentes à cidadania, integrando saúde, previdência e assistência. Assimilando proposições formuladas pelo movimento da Reforma Sanitária Brasileira reconheceu o direito à saúde e o dever do Estado, mediante a garantia de um conjunto de políticas econômicas e sociais, incluindo a criação do Sistema Único de Saúde (SUS), universal, público, participativo, descentralizado e integral.

Atualmente, talvez não caiba discutir os avanços e retrocessos ocorridos na constituinte, nem os limites do texto aprovado. Ao contrário, cumpre ressaltar que a conquista da democracia, depois de 21 anos de ditadura militar, custou vidas, sofrimentos, energias e lutas do povo. Em toda a história da República é a primeira vez que os brasileiros podem comemorar um período tão longo de vigência de um texto constitucional.

Nessa perspectiva, o presente artigo apresenta os seguintes objetivos: (a) resenhar o desenvolvimento das políticas sociais, especialmente na conjuntura pós-constituinte; (b) discutir a evolução de projetos políticos emergentes na transição democrática; (c) analisar problemas e desafios para a sustentabilidade do SUS.

\section{Saúde e proteção social: delimitando as origens}

A análise empreendida parte do pressuposto de que as políticas de saúde integram as políticas sociais, do mesmo modo que o sistema de saúde é um dos componentes dos sistemas de proteção social. Apoia-se em estudos sobre políticas públicas, privilegiando a sua gênese 2 .

"Eis por que, sem dúvida, não há instrumento de ruptura mais poderoso do que a reconstrução da gênese: ao fazer com que ressurjam os conflitos $e$ os confrontos dos primeiros momentos e, concomitantemente, os possiveis excluídos, ela atualiza a possibilidade de que houvesse sido (e de que seja) de outro modo e, por meio dessa utopia prática, recoloca a questão do possível que se concretizou entre todos os outros" 3 (p. 98).

As políticas sociais podem ser analisadas a partir da emergência do capitalismo, quando a questão da pobreza ultrapassa as intervenções resultantes da caridade das famílias e das paróquias e invade as cidades com hordas de famintos, miseráveis, desocupados e delinquentes, durante a transição do feudalismo para o capitalismo, no início do Século XVI. Assim, as primeiras intervenções do Estado aparecem nesse contexto tomando como objeto as carências, sob a forma de assistência social. Diante das proporções da mendicância, a responsabilidade local passou a ser definida pelas Poor Laws, unificadas pela rainha Elizabeth em 1601 4. Essa política foi consolidada com a nova Lei dos Pobres na Inglaterra (1834), incidindo sobre a situação sanitária 5 .

Com o desenvolvimento do capitalismo industrial e o aparecimento da classe operária, a "questão social" ultrapassa a problemática da pobreza e vai manifestar-se enquanto luta de classes. Apresentava-se como expressão das relações sociais capitalistas, especialmente das contradições da infraestrutura econômica e dos seus desdobramentos na superestrutura políticoideológica. Indicava um campo de disputas em função das desigualdades entre as classes sociais, implicando lutas pelo uso de bens e serviços, reconhecidos como direitos no âmbito da cidadania 6 . A criação do seguro social na Alemanha ilustra, assim, uma nova forma de intervenção do Estado a partir da dinâmica das classes sociais e dos processos de industrialização e urbanização.

No Século XX, diante da Revolução Bolchevique, da crise de 1929, das demandas da classe operária e dos sofrimentos decorrentes da Segunda Guerra Mundial, aparece na Europa uma proposta de intervenção do Estado com base na noção de direitos sociais. Os trinta anos de ouro do capitalismo possibilitaram a expansão do Welfare State e o desenvolvimento de modernos sistemas de proteção social. No entanto, a hegemonia conquistada pelos Estados Unidos reorientou a forma de abordar a "questão social", restaurando o foco na pobreza 4 .

Até os anos 50, a internacionalização do alívio à pobreza não era ponto de pauta do Banco Mundial (BM). Posteriormente, modelos econométricos foram desenvolvidos com o apoio do Departamento de Defesa dos Estados Unidos, enquanto o ativismo político dos movimentos sociais defendia os direitos civis. Esse período da Guerra Fria é crucial para o entendimento de como se expande o padrão americano de política social liberal enquanto componente de política externa e da ordem econômica mundial 
instalada, sob sua hegemonia. No bojo dessas políticas cresceu o debate sobre necessidades básicas, cotas e igualdade de oportunidades, enquanto a "questão social" entrava na agenda do BM, relacionando pobreza e fome, além do apoio à reforma agrária. Foram difundidas diversas noções como capital humano, ação comunitária, participação da comunidade, planejamento participativo, empowerment, entre outras. Contar os pobres e delimitar a linha de pobreza tornou-se prioridade, crescendo as pesquisas que produziam evidências estatísticas sobre os efeitos das medidas adotadas para o seu controle. Esse enfoque, baseado em construção de modelos, teste de hipóteses e análises estatísticas tendo o indivíduo como unidade de análise, foi difundido por intermédio de organizações internacionais, especialmente o BM e o Banco Interamericano de Desenvolvimento 4. Portanto, a temática da pobreza foi privilegia$\mathrm{da}$, seja para responder às lutas pelos direitos civis dos negros americanos, seja para justificar a política da Aliança para o Progresso, junto aos países da América Latina, especialmente depois da Revolução Cubana.

Com o neoliberalismo e as mudanças políticas e econômicas, a "questão social" passa a ser foco de controle internacional, condicionando prioridades no que tange aos direitos do trabalho, combate à pobreza e aos sistemas públicos de proteção social, inclusive saúde, assistência, previdência, programas de emprego e subsídios. Ao se deslocarem as negociações internacionais dos produtos para as políticas públicas, elas se tornam mais complexas. Assim, toda uma terminologia foi gerada pela hegemonia americana na gestão da pobreza, como capital social, coesão social, manejo de riscos, tecnologia social, implicando a reformulação da concepção de direitos universais da cidadania. Essa abordagem é apresentada como "científica", capaz de evidenciar a melhor maneira de compatibilizar alguns direitos com sustentabilidade financeira 7 .

\section{A questão social no Brasil e os projetos políticos na transição democrática}

Após as lutas do abolicionismo, a "questão social" emerge com a industrialização e urbanização. A resposta do Estado se faz, preliminarmente, via aparelhos repressivos tratando-a como "caso de polícia” e reprimindo, com violência, as greves operárias. O mesmo Eloy Chaves, responsável em 1922 pela repressão desses movimentos em São Paulo, elege-se deputado e propõe a criação das Caixas de Aposentadorias e Pensões (CAPs), representando uma opção bismarkiana de segu- ro social, visando ao alívio de tensões sociais pela via político-ideológica 8 .

A partir do Golpe de 1930, expande-se a Previdência Social diferenciada por categorias de trabalhadores urbanos. Enquanto o ditador Getúlio Vargas implantava os Institutos de Aposentadoria e Pensões (IAPs) para aqueles vinculados ao mercado formal de trabalho, criava-se a Legião Brasileira de Assistência para os excluídos do mercado e da previdência. Assim, o Welfare State não chegou ao Brasil, que adotou a versão acanhada de "Estado desenvolvimentista" 9. No retorno à democracia em 1945, manteve-se o padrão previdenciário para os trabalhadores e a assistência social para os pobres.

Após a ditadura de 1964, as políticas sociais apresentaram um caráter regressivo no financiamento do gasto social, centralização do processo decisório, privatização do espaço público, fragmentação institucional e reduzido impacto na distribuição da renda 10. Em pleno "milagre econômico" foi "redescoberta" a pobreza diante do agravamento da "questão social", possibilitando que as políticas sociais expandissem na conjuntura pós-1974. O II Plano Nacional de Desenvolvimento (II PND), o Conselho de Desenvolvimento Social (CDS) e o Fundo de Apoio Social (FAS/CEF) eram justificados como "abertura social", precursora da "abertura política”. Entretanto, depois da vitória do partido de oposição em novembro de 1974 ressurgem movimentos sociais e populares, o novo sindicalismo e, na década seguinte, o movimento das Diretas, Já 11.

Com o fortalecimento do Movimento Democrático Brasileiro (MDB), os estrategistas da ditadura acionaram um casuísmo para extinguir o bipartidarismo que eles mesmos inventaram, estimulando a criação de novos partidos, como o Partido dos Trabalhadores (PT) e o Partido do Movimento Democrático Brasileiro (PMDB). Nessa conjuntura teve início o movimento sanitário, defendendo a democratização da saúde, sendo criados o Centro Brasileiro de Estudos de Saúde (CEBES) e a Associação Brasileira de Pós-Graduação em Saúde Coletiva (ABRASCO), e formulada a proposta do SUS 12. Nessa transição democrática podem ser identificados dois projetos alternativos: o Esperança e Mudança e o Democrático Popular.

O primeiro foi formulado pelo PMDB e outras forças oposicionistas, inclusive partidos comunistas postos na ilegalidade, mas abrigados na legenda desde o MDB. Foi gestado mediante encontros e seminários que traziam contribuições de economistas, intelectuais e políticos. Tratavase de um projeto de reforma de cunho nacional, democrático, desenvolvimentista e redistributivo, voltado para o estabelecimento de um Estado 
Social, universal e equânime. Incluía uma agenda política, econômica e social de mudanças, estruturada em quatro eixos: (1) redistribuição de renda como objetivo das políticas públicas e de reforma social; (2) políticas sociais básicas; (3) políticas de reordenamento do espaço e do meio ambiente; (4) emprego, como síntese da política social. A reforma tributária era considerada indispensável para reverter a regressividade do financiamento do gasto social, valorizava-se o controle social e encampava-se parte das propostas do movimento sanitário na direção do SUS público, universal e com gestão descentralizada. Concedia destaque especial para a valorização dos recursos humanos, vigilância sanitária, política científico-tecnológica, produção de vacinas, medicamentos e equipamentos, além da saúde ocupacional. Essa agenda foi construída sob a liderança de forças socialistas e democráticas, possibilitando que as diretrizes políticas, econômicas e sociais fundamentassem os segmentos progressistas nas lutas pela redemocratização até a constituinte 10 .

O segundo projeto foi tecido na construção do PT, articulado aos movimentos sociais, sindicatos e comunidades eclesiais de base, indicando transformações sociais com vistas ao socialismo. Embora sem sistematização de diretrizes, algumas ideias-força foram explicitadas em documentos, bem como nas posições públicas de suas lideranças. Na fundação, afirma-se que o PT nasce das lutas sociais, articulando os interesses dos trabalhadores e dos demais setores explorados pelo capitalismo: "O PT lutará por todas as liberdades civis, pelas franquias que garantem, efetivamente, os direitos dos cidadãos e pela democratização da sociedade em todos os níveis [...]. Por isso, o PT pretende chegar ao governo e à direção do Estado para realizar uma política democrática, do ponto de vista dos trabalhadores, tanto no plano econômico quanto no plano social. O PT buscará conquistar a liberdade para que o povo possa construir uma sociedade igualitária, onde não haja explorados nem exploradores" 13 (p. 382-3).

Ainda que parte dos signatários carregasse uma história de lutas vinculadas ao socialismo, evitou-se utilizar tal palavra nos documentos. No entanto, no discurso de dirigentes e militantes durante a $1^{\text {a }}$ Conferência do Partido dos Trabalhadores essa expressão voltou a aparecer, servindo como referência para o projeto Democrático Popular divulgado nas eleições presidenciais de 1989, por meio da Frente Brasil Popular, composta pelo PT, pelo Partido Comunista do Brasil (PC do B) e pelo Partido Socialista Brasileiro (PSB), com o lema Sem Medo de Ser Feliz 14. Esse projeto foi gestado baseando-se num conjunto de semi- nários com a participação de militantes e intelectuais, contemplando temas de política, economia e políticas sociais 15 . Documentos debatidos naquela oportunidade enfatizavam a retomada do crescimento econômico, a distribuição de renda e a redução das desigualdades. Defendiam uma política de rendas instrumentalizada de forma direta, mediante a elevação do salário mínimo real, e indireta, reformulando políticas sociais de educação, saúde, transporte, saneamento, habitação, entre outras 16. Sem entrar no mérito das disputas internas entre as tendências que constituíram o PT, podem ser constatados desdobramentos desse projeto nos programas apresentados nas eleições seguintes. Propostas como constituição de um mercado de consumo de massa, crescimento econômico com estabilidade, reforma do Estado, reformas previdenciária e tributária e políticas sociais compensatórias passam a integrar o discurso do PT, redefinindo o projeto original. Assim, a crítica ao capitalismo deixava de ter lugar "num projeto político que se compromete em administrar o capitalismo melhor que os capitalistas" 14 (p. 235).

Esses dois projetos foram derrotados eleitoralmente em 1989 na primeira eleição direta para Presidente da República após 21 anos de ditadura. Os partidos que defendiam a Reforma Sanitária Brasileira e o SUS apoiaram Luiz Inácio Lula da Silva e o PT no segundo turno, contra o candidato representante dos liberais, conservadores e remanescentes do autoritarismo.

\section{A redemocratização, a contrarreforma neoliberal e o SUS}

A redemocratização iniciada em 1985 foi marcada por tensões entre propostas assistencialistas e universalizantes que disputavam uma resposta do Estado à dívida social acumulada durante o autoritarismo. Ainda em 1986, foi criado o Grupo de Trabalho de Reformulação da Previdência Social, que propunha a superação da concepção de seguro social para a da Seguridade Social, sob a lógica da solidariedade do Estado de bem-estar social, na qual o "o direito coletivo da cidadania prevaleceria sobre o direito individual associado à contribuição" 10 (p. 162). Recomendava, também, o aumento da cobertura da Renda Mensal Vitalícia criada durante a ditadura, equivalente ao atual Benefício de Prestação Continuada (BPC).

Entretanto, os setores progressistas perderam espaço no Governo José Sarney e forças que apoiaram o regime militar retornaram ao poder. No caso da Reforma Sanitária Brasileira, o retrocesso materializou-se na demissão do presidente do Instituto Nacional de Assistência Médica da 
Previdência Social (INAMPS) em 1988 e no desmonte da estratégia Sistema Unificado e Descentralizado de Saúde (SUDS). O novo Ministro da Previdência e Assistência Social cumpre uma missão junto ao Ministro Antônio Carlos Magalhães no sentido de sustar a Reforma Sanitária na Bahia, considerada uma das experiências mais avançadas do período 10,17. Nessa mesma época foi implantado o Programa Nacional do Leite para Crianças Carentes, considerado emblemático, não só pelo uso clientelista de uma política social focalizada, mas, sobretudo, por sinalizar uma inflexão nas políticas universais.

A disputa com as forças conservadoras reunidas no chamado "centrão" foi intensificada na constituinte, embora a aprovação do capítulo da Seguridade Social sugerisse uma vitória momentânea daqueles que defendiam políticas universais, com destaque para a saúde. Com a nova Constituição a assistência social deixou de ser filantropia estatal, alcançando o estatuto de direito, embora para a cúpula governista os novos direitos sociais eram considerados inimigos da governabilidade. O próprio presidente advertia que artigos do texto constitucional desencorajariam a produção, afastariam capitais e, sendo adversos à iniciativa privada, terminariam por induzir ao ócio e à improdutividade. Desse modo, foram montadas operações pela área econômica, urdidas na Secretaria de Planejamento da Presidência da República e no Ministério da Fazenda, a partir de negociações com o Fundo Monetário Internacional (FMI) no final de 1987, transferindo a gestão do financiamento da Previdência para a Fazenda e dificultando o atendimento dos novos direitos sociais. Esses dirigentes, utilizando argumentos supostamente técnicos de "burocratas domesticados", desviavam os recursos destinados aos programas sociais para cobrirem o déficit público, além de impedirem as transferências de recursos fiscais para a Previdência Social. Ou seja, a União, além de não honrar a sua parte na manutenção da previdência, desviava outra para a ciranda financeira no pagamento da dívida pública 10 .

No período de 1990-2002, foi desenvolvida uma contrarreforma liberal com o desmonte da Seguridade Social e implantado ajuste macroeconômico, por intermédio do Plano Real e da Reforma do Estado:

“Os princípios que orientam o paradigma neoliberal na questão social eram absolutamente antagônicos aos da Carta de 1988: o Estado de Bem-Estar Social é substituído pelo 'estado Minimo'; a seguridade social, pelo seguro social; a universalização, pela focalização; a prestação estatal direta dos serviços sociais, pelo 'Estado Regulador' e pela privatização; $e$ os direitos trabalhistas, pe- la desregulamentação e flexibilização. Em suma, a 'Constituição Cidadã', tão bem alcunhada por Ulysses Guimarães se transformou em 'Constituição vilã', aos olhos dos reformadores liberais e da elite" 10 (p. 390).

O orçamento da Seguridade Social não foi adotado e suas fontes de recursos foram desviadas para financiar a economia. Caso não houvesse a captura de recursos para o pagamento da dívida da União por meio da Desvinculação de Receitas da União (DRU), o orçamento da Seguridade Social seria superavitário 10 . Sendo tais recursos fundamentais para a viabilização das políticas universais como o SUS, identificam-se nessas intervenções determinantes econômicos (subfinanciamento), políticos (contrarreforma liberal) e ideológicos (alívio da pobreza) do redirecionamento das políticas sociais.

As fontes de financiamento da Seguridade Social foram capturadas pela área econômica dos diferentes governos e a "questão social" passou a ser conduzida pelos "programas emergenciais" e de transferência, condicionada de renda que se tornaram permanentes. Essa opção liberal e conservadora, preconizada por instituições internacionais de fomento, tem sido defendida por especialistas e por governos considerados de esquerda.

Novas "crises" da previdência foram fabricadas para justificarem as reformas nos governos de Fernando Henrique Cardoso (FHC), Lula e Dilma Rousseff, tendo o suposto déficit como pretexto. De acordo com os tecnoburocratas, os recursos da União deveriam reforçar o capitalismo, desonerando o capital, prevalecendo uma regra pétrea entre os economistas do poder segundo a qual o gasto social não deve pressionar o orçamento fiscal 10. Mas quando ressurge a crise, como nos mandatos de FHC e de Lula, os recursos da União foram usados para socorrer a economia. Desse modo, R\$ 180 bilhões do Tesouro Nacional foram direcionados ao Banco Nacional de Desenvolvimento Econômico e Social (BNDES) para enfrentar a crise de 200818.

Contudo, para uns o Brasil mudou para melhor 19, apesar das continuidades 20 , adotando políticas públicas que resultaram em crescimento com distribuição de renda 21 e participação social 22 . Outros apontam certa mobilidade na base da estrutura social, com reforço do contingente de trabalhadores 23 , e um realinhamento político-eleitoral traduzido pelo "lulismo", mediante um "reformismo fraco" no qual burgueses e proletários são substituídos por ricos e pobres no discurso político 24 . Já a crítica interpreta de outro modo as mudanças operadas: "Essa é $a$ base do 'novo consenso', do 'crescimento com distribuição' na era do capital financeiro, que levou à 
incorporação marginal de parcelas da população de menor renda ao consumo, tendo como contrapartida a desmobilização política dos movimentos sociais e dos sindicatos, a tutela direta do Estado sobre a parte da população mais pobre, a despolitização da política, a desqualificação ainda maior dos partidos, e como resultado disso tudo o surgimento, desenvolvimento e consolidação do 'lulismo'” 25 (p. 64).

Em síntese, traduzindo a ideologia neoliberal para as políticas estatais, o Governo Fernando Collor intensificou a abertura da economia e, após o impeachment, o Governo Itamar Franco optou por um ajuste macroeconômico. Elegendo o Presidente da República em 1994 o Partido da Social Democracia Brasileira (PSDB), em aliança com o Partido da Frente Liberal (PFL), PMDB e outras legendas, distancia-se do projeto Esperança e Mudança, bem como da social-democracia, desenvolvendo uma agenda neoliberal. Conquistando a presidência a partir de 2002 o PT, com o apoio de partidos de esquerda, PMDB e pequenos partidos, deu continuidade às políticas do Governo FHC num sentido diverso do projeto Democrático Popular original, aproximando-se do liberalismo social. Esses dois projetos que emergiram na transição democrática não foram derrotados apenas em 1989. Mesmo quando tiveram a oportunidade histórica de chegar ao governo da República foram transfigurados pelos gestores do capital, bem como pelo transformismo dos sujeitos políticos.

Ainda assim, todos esses governos prestaram alguma contribuição ao SUS: Sarney implantou o SUDS; Collor sancionou as Leis Orgânicas da Saúde; Itamar criou o Programa Saúde da Família (PSF), extinguiu o INAMPS e avançou a descentralização; FHC ampliou o PSF, implantou a política dos medicamentos genéricos e organizou a Agência Nacional de Vigilância Sanitária (ANVISA) e a Agência Nacional de Saúde Suplementar (ANS); Lula montou o Serviço de Atendimento Móvel de Urgência (SAMU) e implementou as políticas de saúde mental e bucal 26; Dilma regulamentou a Lei no 8080/90 e aprovou a Lei Complementar 141 27. Nenhum deles, porém, incorporou a Reforma Sanitária Brasileira como projeto de governo, nem demonstrou um compromisso efetivo com o SUS nos termos estabelecidos pela Constituição de 1988.

\section{Políticas sociais, Reforma Sanitária Brasileira e o SUS}

A retórica sobre a pobreza vem desde o Governo Sarney 28 , mas o predomínio das políticas focalizadas começa em 1990 com o discurso dos "des- camisados", e adquire força na criação do Fundo de Combate à Pobreza. Essa proposta foi apresentada no Instituto de Cidadania, com o apoio de Lula, e viabilizada em 2000 com recursos da Contribuição Provisória de Movimentação Financeira (CPMF). Com esse fundo foi efetivada a incorporação da transferência condicionada de renda na agenda do Governo FHC.

"É importante ressaltar que a contra-reforma liberal encontrou um grande aliado no Partido dos Trabalhadores, o senador Eduardo Suplicy [...]. Dentre as iniciativas dessa cruzada, destacam-seo PLS 66/99 que institui a 'Linha Oficial de Pobreza' e o que institui o 'Fundo Brasil Cidadania' (PLS 82/99), base para o Fundo de Combate à Pobreza por iniciativa de ACM [...], espelhando a coerência do senador baiano com seu passado conservador. A cruzada vitoriosa do senador do PT consumouse a partir de 2003 no âmbito do governo Luiz Inácio Lula da Silva" 10 (p. 540).

A política social no Brasil ficou reduzida ao assistencialismo das políticas focalizadas, 6,29 e no período 2003-2012 consolidou o processo de americanização na reconversão da "questão social”. A agenda governamental foi concentrada nas políticas de redução da pobreza, tendo o Bolsa Família como carro-chefe, reiterando a opção neoliberal do período anterior: “ $A$ opção neoliberal rasgou a Constituição da República, enterrou a Seguridade Social e o Orçamento da Seguridade Social, esterilizando suas fontes de recursos na 'gestão' da dívida pública. A lição de casa foi feita de forma exemplar, sob o aplauso dos financistas, ampliando o ajuste fiscal e as possibilidades de seguir avante no pagamento de juros aos rentistas, dando sequência ao mais extraordinário programa de transferência de renda para os endinheirados de que se tem notícia na história do Brasil" 10 (p. 461).

O Bolsa Família passou de 3 milhões em 2003 para 12,3 milhões de famílias em dezembro de 2009, acompanhado da queda do coeficiente de Gini de 0,580 para 0,538 20. Os gastos com o BPC, Bolsa Família, saúde pública, previdência social e na educação pública são apontados como responsáveis pela redução do Gini em 2,3\%, 2,2\%, $1,5 \%, 1,2 \%$ e $1,1 \%$, respectivamente 30 . Ainda assim, o Brasil é atualmente o $4^{\circ}$ país mais desigual da América Latina. O Gini melhorou, mas não consegue revelar a desigualdade de rendimento entre o capital e o trabalho. Em 2011 o Governo Federal destinou 5,72\% do Produto Interno Bruto (PIB) para o pagamento dos juros e $0,4 \%$ para o Bolsa Família (13.330.714 famílias cadastradas). Para os ricos uma "doação" 13 vezes maior 31 .

Desenvolveu-se no país certa unanimidade na ideia de que política social é para pobres, paralelamente ao desmonte institucional, orça- 
mentário e conceitual da Seguridade Social. O "neo-assistencialismo" e o glamour dos pobres são reificados pelo "mundo apartheizado do banco popular, da agricultura familiar, dos eletrodomésticos e da economia solidária" 32 (p. 77). Mas na realidade a transferência de renda com condicionalidade cumpre o receituário liberal do $\mathrm{BM}$, ainda que seja eticamente discutível diante da dignidade da pessoa humana e "frente a $\mathrm{um}$ direito anterior que é a garantia à vida, portanto à subsistência dessas famílias" 6 (p. 210).

Na série sobre saúde no Brasil do The Lancet 33 foram apontadas inúmeras conquistas do SUS, sobretudo na ampliação do acesso aos serviços de saúde, com repercussões positivas no perfil epidemiológico. No entanto, inovações institucionais, descentralização, participação social, consciência do direito à saúde, formação de trabalhadores e tecnologias convivem, contraditoriamente, com o crescimento do setor privado, segmentação do mercado e comprometimento da equidade nos serviços e nas condições de saúde. Entre os obstáculos destacaram-se a diminuição do financiamento federal, as restrições de investimento em infraestrutura e a gestão do trabalho 26 .

Há uma dívida histórica com os trabalhadores que construíram o SUS, submetidos à precarização do trabalho e a terceirizações, sendo adiada a efetivação de planos de carreiras, cargos e salários. Portanto, ainda há muito que fazer para tornar o SUS universal e público, bem como para assegurar padrões elevados de qualidade. Seus maiores desafios são políticos, pois supõem a garantia do financiamento do subsistema público, a redefinição da articulação público-privada e a redução das desigualdades de renda, poder e saúde.

No mesmo ano em que esses estudos eram publicados, dois poderes da República rejeitaram a proposta de comprometimento de pelo menos $10 \%$ do orçamento da União para a saúde. Adiou-se, mais uma vez, o fortalecimento do SUS, sugerindo que pode até haver ministros sanitaristas, mas sem recursos para operálo 34 . Desse modo, o subfinanciamento público, a persistência de desigualdades na oferta e a articulação público-privada prejudicial ao SUS impedem o cumprimento do que está estabelecido na Constituição, nas leis ordinárias, decretos e demais documentos.

Costa et al. 35 analisam posições ambíguas do governo Dilma em relação à articulação público-privada e denunciam ameaças contra o SUS decorrentes de pressões dos que apostam na privatização, tanto nos setores à direita quanto à esquerda do espectro político. Alertam que mais subsídios e desonerações fiscais para a expansão do mercado de assistência médica suplementar deparam com um acúmulo de experiências negativas de consumidores iludidos de que o mercado seria capaz de atender suas necessidades. Portanto, não se vislumbra um cenário otimista para a sustentabilidade do SUS 36 . Mesmo conseguindo-se mais recursos, outras lutas serão necessárias para evitar o modelo americano e não permanecer refém da indústria de equipamentos e de medicamentos, dos hospitais privados e do corporativismo de profissionais 37 .

Talvez a sociedade brasileira tenha aprendido nesses 25 anos que não basta dispor de uma Constituição e de uma legislação para as mudanças ocorrerem. Observa que na democracia representativa adotada pelo Brasil os governantes, na maioria das vezes, não seguem os programas dos partidos muito menos aquilo que apresentam durante as campanhas. Além disso, certas lideranças e partidos que defendiam a Reforma Sanitária Brasileira e o SUS fortaleceram as fileiras dos que apostam na privatização, reproduzindo o transformismo na saúde. Novos esforços são necessários para revitalizar a sociedade civil, na qual tem origem a Reforma Sanitária Brasileira e o SUS, tentando desequilibrar o binômio da "conservação-mudança" contra a inércia da conservação 38 .

\section{Comentários finais}

Na América Latina a privatização dos sistemas de saúde não se mostrou efetiva, gerando pouco aumento de cobertura. Parte dos países adotou copagamento, com barreira de acesso e custos administrativos, e no caso colombiano, tão festejado pela Organização Mundial da Saúde (OMS) e BM, o sistema beira a insolvência: os gastos de saúde quase triplicaram sem universalidade do acesso, integralidade e melhoria nos indicadores de saúde 39 .

No Brasil, verifica-se uma redução da contribuição do governo federal nos gastos com o SUS. Em 2008, a participação da saúde na receita da Seguridade Social decresceu para $14,5 \%$, inferior àquela verificada antes do SUS, igual a 18\% no início da década de 80 e 30\% em 198840. Portanto, pensar os 25 anos do SUS à luz das políticas públicas e da Reforma Sanitária Brasileira, supõe olhar o Brasil para além das aparências midiáticas e do discurso oficial. Em dezembro de 2011 a dívida pública ultrapassava $\mathrm{R} \$ 3$ trilhões, maior que o dobro do orçamento federal daquele ano. A dívida externa que muitos imaginavam ter sido paga estava em US\$402,3 bilhões e a interna correspondia a R \$ 2,536 trilhões (http:/ / www. jubileusul.org.br). 
Portanto, grandes desafios continuam postos para a Reforma Sanitária Brasileira e a consolidação do SUS, enquanto sistema de saúde público, universal, igualitário, integral e de qualidade. Novas questões, conceitos, hipóteses explicativas e pesquisas são necessários para decifrar os aparentes paradoxos dos governos Lula-Dilma na saúde. Uma hegemonia às avessas ${ }^{41}$ parece ser construída pelas forças que defendem o SUS, pois na aparência constata-se uma direção cultural e moral, quando integrantes do movimento sanitário chegam a ocupar posições de governo, a ponto de um ex-presidente do CEBES tornarse ministro da saúde, mas na essência prevalecem os interesses do capital, assegurados por seus representantes dentro e fora do setor 42 . Do mesmo modo, a forma pela qual as classes dominantes têm atuado em relação ao Estado e às classes subalternas no Brasil 43, favorecendo o transformismo e a revolução passiva 44 , explica as características do processo da Reforma Sanitária Brasileira e da implementação do SUS 38. Diante desse quadro, quais projetos se esboçam? De um lado, "a nova agenda social" 45, que propõe a reatualização e intensificação das reformas da "era FHC" 46. De outro, o "neodesenvolvimentismo", explicitado nas prospecções para o Brasil em 203047.

Resta às forças progressistas da sociedade civil apostar nos portadores da antítese $38,43,48$ que tendem a emergir dos movimentos sociais, identificando distintos antagonismos na sociedade contemporânea ${ }^{49}$. Uma atenção especial para a pluralidade de vozes numa sociedade democrática permitiria constituir sujeitos políticos individuais e coletivos que questionem a subversão dos direitos sociais, as iniquidades em saúde e as relações de subordinação, desencadeando novas ações políticas.

Esperança e Mudança e Democrático Popular foram projetos possíveis, excluídos pelos filtros da revolução passiva brasileira. Ainda assim, põem em questão o possível que se concretizou ${ }^{3}$, pois as forças políticas que alcançaram o poder nas últimas décadas não apresentaram um projeto para a Nação à altura daqueles que geraram a Constituição Cidadã. Trata-se agora, de reinventá-lo.

\section{Resumen}

Este artículo, que celebra los 25 años de la Constitución de 1988, tiene por objetivo revisar el desarrollo de las políticas sociales, discutir los proyectos y analizar los desafíos políticos para la sostenibilidad del Sistema Único de la Salud brasileño (SUS). Basándose en estudios de políticas públicas que favorecieron su génesis, revisa los orígenes de la política socio liberal, centrada en la asistencia social, y analiza la hegemonía de las políticas estadounidenses destinadas a la pobreza y su impacto en las políticas universales. Después de identificar la formulación de proyectos políticos en la transición democrática brasileña, discute sus implicaciones en los siguientes gobiernos, junto a las dificultades que enfrenta el SUS. Concluye que las fuerzas políticas que llegaron al poder en las últimas dos décadas no han presentado un proyecto para la nación a la altura de los que genera la Constitución ciudadana.

Política de Salud; Sistemas de Salud; Sistema Único de Salud; Política Social

\section{Agradecimentos}

Às professoras Lígia Maria Vieira da Silva e Carmen Teixeira pelas valiosas sugestões e revisão geral do texto. 


\section{Referências}

1. Marx K. Crítica da filosofia do direito de Hegel. São Paulo: Boitempo Editorial; 2005. p. 146-147.

2. Pinell P. Análise sociológica das políticas de saúde. Rio de Janeiro: Editora Fiocruz; 2010.

3. Bourdieu P. Razões práticas. Sobre a teoria da ação. Campinas: Papirus Editora; 1997.

4. Mauriel APO. Capitalismo, políticas sociais e combate à pobreza. Ijuí: Editora Unijuí; 2011.

5. Donnangelo MCF. Saúde e sociedade. São Paulo: Duas Cidades; 1976.

6. Silva MOS, Yazbek MC, Giovanni G. A política social brasileira no século XXI. A prevalência dos programas de transferência de renda. São Paulo: Cortez Editora; 2004.

7. Vianna MLTW. Prefácio. In: Mauriel APO. Capitalismo, políticas sociais e combate à pobreza. Ijuí: Editora Unijuí; 2011. p. 11-5.

8. Donnangelo MCF. Medicina e sociedade: o médico e seu mercado de trabalho. São Paulo: Pioneira; 1975.

9. Fiori JL. Em busca do dissenso perdido. Ensaios críticos sobre a festejada crise do Estado. Rio de Janeiro: Insight Editorial; 1995.

10. Fagnani E. Política social no Brasil (1964-2002): entre a cidadania e a caridade [Tese de Doutorado]. Campinas: Instituto de Economia, Universidade Estadual de Campinas; 2005.

11. Maués F, Abramo ZW, organizadores. Pela democracia, contra o arbítrio: a oposição democrática, do golpe de 1964 à campanha das Diretas Já. São Paulo: Editora Fundação Perseu Abramo; 2006.

12. Centro Brasileiro de Estudos de Saúde. A questão democrática na área de saúde. Saúde Debate 1980; 9:11-3.

13. Manifesto aprovado na reunião do Colégio Sion. In: Maués F, Abramo ZW, organizadores. Pela democracia, contra o arbítrio: a oposição democrática, do golpe de 1964 à campanha das Diretas Já. São Paulo: Editora Fundação Perseu Abramo; 2006. p. 381-3.

14. Coelho E. Uma esquerda para o capital. Crise do Marxismo e mudanças nos projetos políticos dos grupos dirigentes do PT (1979-1998) [Tese de Doutorado]. Niterói: Programa de Pós-Graduação em História, Universidade Federal Fluminense; 2005.

15. Weffort F, organizador. PT: um projeto para o Brasil. São Paulo: Brasiliense; [1989?].

16. Decca C, Mattoso JE. Distribuição da renda e redução das desigualdades: política de rendas e governo democrático popular. In: Weffort F, organizador. PT: um projeto para o Brasil. São Paulo: Brasiliense; [1989?]. p. 35-57.

17. Molesini JAO. A Reforma Sanitária na Bahia: um lugar na história (1987-1989) [Tese de Doutorado]. Salvador: Faculdade de Enfermagem, Universidade Federal da Bahia; 2011.

18. Tautz C, Siston F, Pinto, JRL, Badin L. O BNDES e a reorganização do capitalismo brasileiro: um debate necessário. In: Os anos Lula: contribuições para um balanço crítico 2003-2010. Rio de Janeiro: Garamond; 2010. p. 249-86.

19. Sader E, Garcia MA, organizadores. Brasil entre o passado e o futuro. São Paulo: Editora Fundação Perseu Abramo/Boitempo; 2010.
20. Machado CV, Baptista TWF, Lima LD, organizadores. Políticas de saúde no Brasil: continuidades e mudanças. Rio de Janeiro: Editora Fiocruz; 2012.

21. Barbosa N, Souza JAP. A inflexão do governo Lula: política econômica, crescimento e distribuição de renda. In: Sader E, Garcia MA, organizadores. Brasil entre o passado e o futuro. São Paulo: Editora Fundação Perseu Abramo/Boitempo; 2010. p. 57110 .

22. Dulci LS. Participação e mudança social no governo Lula. In: Sader E, Garcia MA, organizadores. Brasil entre o passado e o futuro. São Paulo: Editora Fundação Perseu Abramo/Boitempo; 2010. p. 133-52.

23. Pochmann M. Nova classe média? O trabalho na base da pirâmide social brasileira. São Paulo: Boitempo; 2012.

24. Singer AV. Os sentidos do lulismo: reforma gradual e pacto conservador. São Paulo: Companhia de Letras; 2012.

25. Filgueiras L, Pinheiro B, Philigret C, Balanco P. Modelo liberal-periférico e bloco de poder: política e dinâmica macroeconômica nos governos Lula. In: Os anos Lula: contribuições para um balanço crítico 2003-2010. Rio de Janeiro: Garamond; 2010. p. 35-69.

26. Paim JS, Travassos C, Almeida C, Bahia L, Macinko J. The Brazilian health system: history, advances, and challenges. Lancet 2011; 377:1778-97.

27. Santos, L. SUS e a Lei Complementar 141 comentada. Campinas: Saberes Editora; 2012.

28. Abranches SH, Santos WG, Coimbra MA. Política social e combate à pobreza. 2a Ed. Rio de Janeiro: Jorge Zahar Editor; 1989.

29. Soares LTR. Ajuste neoliberal e desajuste social na América Latina. Rio de Janeiro: Editora UFRJ; 1999.

30. Viana MLA, Silva HP. Desenvolvimento e institucionalidade da política social no Brasil. In: Machado CV, Baptista TWF, Lima LD, organizadores. Políticas de saúde no Brasil: continuidades e mudanças. Rio de Janeiro: Editora Fiocruz; 2012. p. 31-60.

31. Rossi C. Desigualdade, o fracasso da esquerda. Folha de São Paulo 2012; 26 ago.

32. Vianna MLTW. O culpado é o mordomo? Constrangimentos outros (que não os do modelo econômico) à seguridade social. In: Lobato LVC, Fleury S, organizadores. Seguridade Social, Cidadania e Saúde. Rio de Janeiro: Cebes, 2009. p. 66-83.

33. Victora CG, Leal MC, Barreto ML, Schmidt MI, Monteiro CA, organizadores. Saúde no Brasil: a série The Lancet, 2011. Rio de Janeiro: Editora Fiocruz; 2011.

34. Bahia L. A saúde em banho-maria. In: Os anos Lula: contribuições para um balanço crítico 20032010. Rio de Janeiro: Garamond; 2010. p. 351-68.

35. Costa AM, Bahia L, Scheffer M. Onde foi parar o sonho do SUS? Le Monde Diplomatique Brasil 2013; 69:30-1.

36. Paim JS. O futuro do SUS. Cad Saúde Pública 2012; 28:612-3.

37. Ocké-Reis CO. SUS: o desafio de ser único. Rio de Janeiro: Editora Fiocruz; 2012. 
38. Paim JS. Reforma Sanitária Brasileira: contribuição para a compreensão e crítica. Salvador: Edufba/ Rio de Janeiro: Editora Fiocruz; 2008.

39. Borges FT, Moimaz SAS, Siqueira CE, Garbin CAS. Anatomia da privatização neoliberal do Sistema Único de Saúde: o papel das Organizações Sociais de Saúde. São Paulo: Cultura Acadêmica; 2012.

40. Noronha J, Santos I, Pereira T. Relações entre o SUS e a saúde suplementar: problemas e alternativas para o futuro do sistema universal. In: Santos NR, Amarante PDC, organizadores. Gestão pública e relação público-privado na saúde. Rio de Janeiro: Centro Brasileiro de Estudos de Saúde; 2011. p. 152-79.

41. Oliveira F, Braga R, Rizek C, organizadores. Hegemonia às avessas. São Paulo: Boitempo; 2010.

42. Paim JS. SUS: desafios e perspectivas. Consensus. Revista do Conselho Nacional de Secretários de Saúde 2011; 1:33-6.

43. Vianna LW. Caminhos e descaminhos da revolução passiva brasileira. In: Aggio A, organizador. Gramsci, a vitalidade de um pensamento. São Paulo: Fundação Editora Unesp; 1998. p. 185-201.

44. Gramsci A. Cadernos do cárcere. Rio de Janeiro: Civilização Brasileira; 2002.
45. Bacha EL, Schwartzman S, organizadores. Brasil: a nova agenda social. Rio de Janeiro: LTC; 2011.

46. Lamounier B, Figueiredo R, organizadores. A era FHC, um balanço. São Paulo: Cultura Editores Associados; 2002.

47. Fundação Oswaldo Cruz. A saúde no Brasil em 2030. Diretrizes para a prospecção estratégica do sistema de saúde brasileiro. Rio de Janeiro: Fundação Oswaldo Cruz/Instituto de Pesquisa Econômica Aplicada/Ministério da Saúde/Secretaria de Assuntos Estratégicos da Presidência da República; 2012.

48. Vianna LW. A revolução passiva: iberismo e americanismo no Brasil. 2a Ed. Rio de Janeiro: Revan; 2004.

49. Laclau E, Mouffe C. Hegemonia y estrategia socialista. Hacia uma radicalización de la democracia. 3a Ed. Buenos Aires: Fondo de Cultura Económica; 2010.

Recebido em 14/Mai/2013

Aprovado em 05/Jun/2013 